\title{
EFL Teachers' Attitude Towards Accent of Effective ELF Communication
}

\author{
Nurul Noviana \\ ms.nurulnoviana@gmail.com
}

Retno Muljani

retnomuljani@usd.ac.id

Sanata Dharma University, Yogyakarta

\begin{abstract}
Over the years, English is best intended to be taught by a native speaker. Ironically, both native speakers and non-native speakers need to enhance their efficiency. As a qualified instructor of English, the habit of using accent preferences may affect interaction. This methodological research, therefore, examines the extent to which the English as Lingua Franca (ELF) reference is rendered in the EFL classroom. By categorizing the open-ended question as to the first survey and continue to gather in-depth interviews, the perspectives on ideological preferences on particular accents were identified. As a result, the findings suggest that accents are not significant, preferably the usage of language between interlocutors to communicate has been proposed further.
\end{abstract}

Keywords: EFL teachers, attitude, accent, ELF

\section{INTRODUCTION}

In earlier studies, standard English, substantial confusion and disagreement over what English format, how to satisfy teachers and students in their multilingual classrooms became extremely difficult to identify (Jenkins, 2006). Language has been rooted over the years. In other words, only American and British were noticed in English on both sides. In the wake of the emergence of English as a global language, English is often used by speakers from different languages and communities who do not share a shared first language (Sung, 2014b).

The notion of English as Lingua Franca (ELF) reported the bridges to simplify the ideological native-speakerism. The previous studies establish the understanding of ELF as a dynamic process of learning English and remind fluid to be utilized (Kirkpatrick, 2012; Chen, Ren, \& Lin, 2019). Furthermore, the new methodology was proposed due to the transformation of English globalization today. It is called Translanguaging (Wei, 2016) to dominate the purism of one language only in the context of bilingualism and multilingualism. Besides, the integration of Conversation Analysis (CA) has been previously proposed to increase the overall communication abilities of students (Teng \& Sinwongsuwat, 2015). With a different point of view of English usage, Received Pronunciation (RP) has reported as a tool to preferred a selection of statements as they felt it was simpler to comprehend (Carrie, 2017), meanwhile to propose a course for teacher-education services to train standard school teachers for effective communication with language minorities, both in their maintenance and operation (Byrnes, Kiger, \& Manning, 1997). Alternatively, the restricted role of monolingual standard English in 
broad regions, and the capacity of multilingual and multilingual English consumers in this $21 \mathrm{st}$ century, must be taken into account (Ishikawa, 2020).

Multicultural existence of established classrooms also causes challenges that may become barriers to the development of the academic method of various regions. ELF speakers should adapt their language to be intelligible to interlocutors of a wide range of L1 (Jenkins, 2006). In the context of the EFL classroom, the local teacher as the role model in speaking English (Ur, 2010) unspecifying whether a native speaker or non-native speaker charges the crucial role to be followed by the students. At the same time, not all native speaker uses the same English variety (Ur, 2010). The confusion of language identity blurry immersed and shared. Anecdotally, in previous studies, notice that teachers felt that in the new school, the native speaker paradigm was no longer important and did not think that the changing points of view of pronunciation teaching had influenced their teaching (Andersson, 2020).

To support the role of EFL teachers in the preferences accents to communicate with the students, it has to analyze the ELF effectiveness. The belief of a native speaker and non-native speaker required particular proficiency to meet the English language teacher's quality. Teachers with a constructive outlook about similarities and individuality are likely to encourage students to become persons who become optimistic towards other people's differences. Teachers' optimistic attitudes are mirrored in their behaviors and the environment that they build each day throughout their teaching cycle. In conclusion, this paper reports the study of EFL teachers' preferences toward accents in the use of ELF communication.

\section{LITERATURE REVIEW}

\section{Defining Accents, Attitudes, and ELF}

Lingua franca is comprising essential phonological, morphosyntactic, and pragmatic characteristics of ELF (Nagy, 2017). Instead, Jenkins (2000) utilizes lingua franca core for elements of pronunciation crucial to understand communication in face-to-face lingua franca. It is argued that accents in the use of the English language get a positive attitude. The previous study from (Meerleer, 2011), the result shows that the classes in question favored native accents, which were higher in terms of social standing. For instance, correcting pronunciation was categorized as native speakers' norms. It is also supported in other studies that such accents were regarded by students as appropriate templates for speaking, which showed the suitability of the speakers as ELTs (Tsang, 2020).

Interestingly, since accents were fluid and varied (Sung, 2014a), the attitudes toward learners acquire the language was debated by (Alqahtani, 2012) that the argument that students are overgeneralized in their ability to preserve their identities by speaking in English, and that the mindset of a student may be different from that of another. ELF should mainly be considered as a communication tool and not as an array of languages; a standard class variety can not be replaced (Nagy, 2017). In other mix-method studies from (Kustati, Yusuf, Hallen, Al-Azmi, \& Sermal, 2020) reported that teachers who have a less appropriate attitude in favor of multicultural students continue to deliver pupils with fewer English credentials.

The principal aim of English as Lingua Franca (ELF) study today is to explain some of the forms ELF interaction happens in individual cultures, but in particular to illustrate the pragmatic strategies utilized by speakers while engaging in conversation (Cogo, 2012). The importance of understanding between interlocutors is the main idea of ELF. It is targeted at 
raising understanding, making students conscious of various means of talking English, variation in vocabulary, shifts and offering them a preference, i.e., whether they choose to communicate like mother-tongue speakers, however, they can talk ELF, and that can in some instances be much more fitting (Cogo, 2012).

ELF is not either monolithic or a selection since cultural and linguistic capital must ultimately be converted into locally appropriate resources (Cogo, 2012). There is a particular intention on the reason that ELF has been existed due to the local attention to student's comprehension first. ELF as a linguistic concept and regards ELF as ungrammatical English attention (Rahayu, 2019), language variation, the latter identifies ELF from a sociolinguistic perspective and defines ELF as a tool instead of a linguistic diversity (Nagy, 2017). The presence of ELF in the classroom will also occur under different terms and circumstances. The purpose and the objective of teaching should be clear as well. Thus, negotiation and adaptation are the main characteristics of the ELF: speakers communicate about their importance in a dialogue that adapts their partners 'skills and needs to those of their interlocutor (Nagy, 2017).

ELF is one means of recognizing the usage of English. ELF is the knowledge of teachers' and students' preferences. Language, as can be shown, is not just an American or British Native tongue, but much more. It is like a variation in English because ELF struggles with the significance of the tendency of speakers to change or adjust their English language habits so that their interlocutors recognize what their speeches. The pattern may vary with the language in various contexts.

\section{The link between ELF and Native-speaker}

The teachers are strongly influenced by their English learning experience, their English language skills, their national identity, and their English culture (Danping, 2013). Concerning the aims of language learning, English could be viewed as an ' Asian, ' an expression spoken by multilingual, for whom it would be meaningless to achieve idealized native speaker standards. Asian multilingual may instead be measured against the "expectations" of active Asian multi-liner speakers (Kirkpatrick 2007) instead of being measured against the rules of the idealized single-lingual native speaker.

Nevertheless, the theory that the ideal teacher is the native speaker remains robust, even in multilingual settings where English is a lingua franca (Kirkpatrick, 2012). Teachers can not be assessed on their native/non-native status based on their academic credentials, technical expertise, and experience (Floris \& Renandya, 2020). ELF can be either: a language, an actual variety of English, distinct from native varieties, or a context or purpose of use (Ur, 2010). It is also supported in the research result that, in the sense of different discourse in English, it seems unreasonable to ask students to follow native-speaker norms and habits, as it has been discovered that the native English speaker varieties are not often the most understandable (Kaur, 2018).

ELF as sociolinguistic prospective teachers (Ur, 2010; Reko, 2019) to mainly commit to ensuring excellent and useful education for his or her students. In teaching English, teachers often follow the native speaker principles of text type, but they use the ELF method to help students in utilizing their vocabulary repertoire (Ke \& Cahyani, 2014). A teacher must be multilingual who may also develop sufficient inter-cultural competence among the learners. Therefore, a "local" multilingual instructor provides both a language and cultural model for 
students; both the multilingual nature of the learner and the teacher are recognized as a positive tool to enable bilingual or multilingual pedagogy to assist the learner in acquiring English. Trust in the use of the ELF in education seems to have been influenced by a range of factors, including linguistic knowledge, this language ability, culture and country values, and the status of a foreign language (Danping, 2013).

In other terms, a lingua franca method treats teachers' and students ' multilingual identity as an asset to be utilized (Kirkpatrick, 2012). Influence ELF belief: "English language learning experience, English language proficiency as the career development, nationality - equality and language justice are not preserved by entirely depriving people of their language rights by relying on the principle of L1, English language identity: a significant element affecting the opinions on the usage of English was the international language identity of teacher participants" (Danping, 2013).

The indigenous language is often originated from western civilization, where the original English language developed. In addition to the presence of initial English, there were first suggested English language teaching methods and methodologies. Given the Linguistic position in the world Language, ELF wanted to allow citizens to understand each other. Today, L1 and L2 tend to be uncategorized as the primary language law. The expertise issues are not just the ethnicity and the rank of the speaker. $E L F$, though, as a "communication" language, anticipates confusion and misunderstandings in the English language during the discussions.

\section{METHOD}

A qualitative study was attempted to examine the use of ELF to communicate in the perspective of teachers as the framework because the rationale of this approach is that various viewpoints provided by specific study frameworks are evaluated against each other (Mays \& Pope, 2019). This study was conducted to investigate the question:

1. What are the general views of utilizing accents to the context of language learners?

2. To what extent is ELF included in EFL classes in the learning process? 


\section{Context and participants}

Table 1. Participants Profile

\begin{tabular}{|l|l|l|}
\hline $\begin{array}{c}\text { Participant } \\
\text { (P) }\end{array}$ & $\begin{array}{c}\text { Teaching } \\
\text { experience } \\
\text { (Month) }\end{array}$ & \multicolumn{1}{|c|}{ Lived abroad } \\
\hline P1 & 72 & less than 2 months \\
\hline P2 & 48 & No \\
\hline P3 & 12 & No \\
\hline P4 & 120 & No \\
\hline P5 & 6 & 8 months \\
\hline P6 & 228 & 3 years \\
\hline P7 & 266 & No \\
\hline P8 & 247 & No \\
\hline P9 & 168 & No \\
\hline P10 & 20 & No \\
\hline P11 & 276 & 30 years \\
\hline P12 & 240 & No \\
\hline P13 & 180 & 2 days \\
\hline P14 & 188 & No \\
\hline P15 & 60 & 1 year \\
\hline P16 & 84 & No \\
\hline
\end{tabular}

The setting of this study was to investigate 16 random teachers in international teacher's forum who are willing to fill the survey. The profile who participated in the survey can be seen in Table 1. The expert teacher who has experienced in teaching English and lived abroad filled the ten open-ended questions shows the categorization which influences the findings. In this forum, ELF usage may occur since the students come from different countries.

\section{Figure 1. Participants' Nationality}

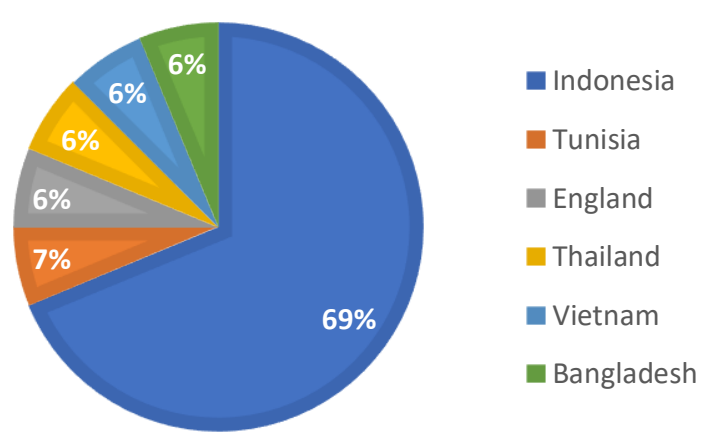

Figure 2. Participants' Education

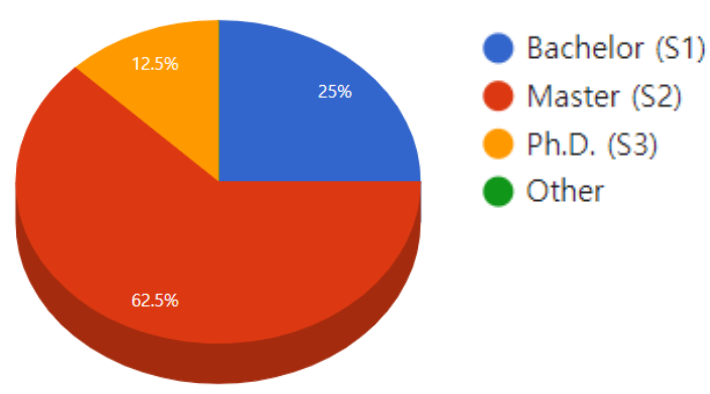


The two pie charts above conclude the survey is picturing the participant' nationality and education. Turning to the first figure, it shows the participants are $69 \%$ from Indonesia, and the following percentage of $7 \%$ and $6 \%$ are Tunisia, England, Thailand, Vietnam, and Bangladesh. Meanwhile, figure 2 illustrates the level of education of this research. Most of them, 62,5\%, are coming from a Master's degree, $25 \%$ represents a Bachelor's degree, and 12,5\% Ph.D. They are taking closer to figure 3, distributing the participants' profiles in this study.

\section{Figure 3. School Level of Taught}

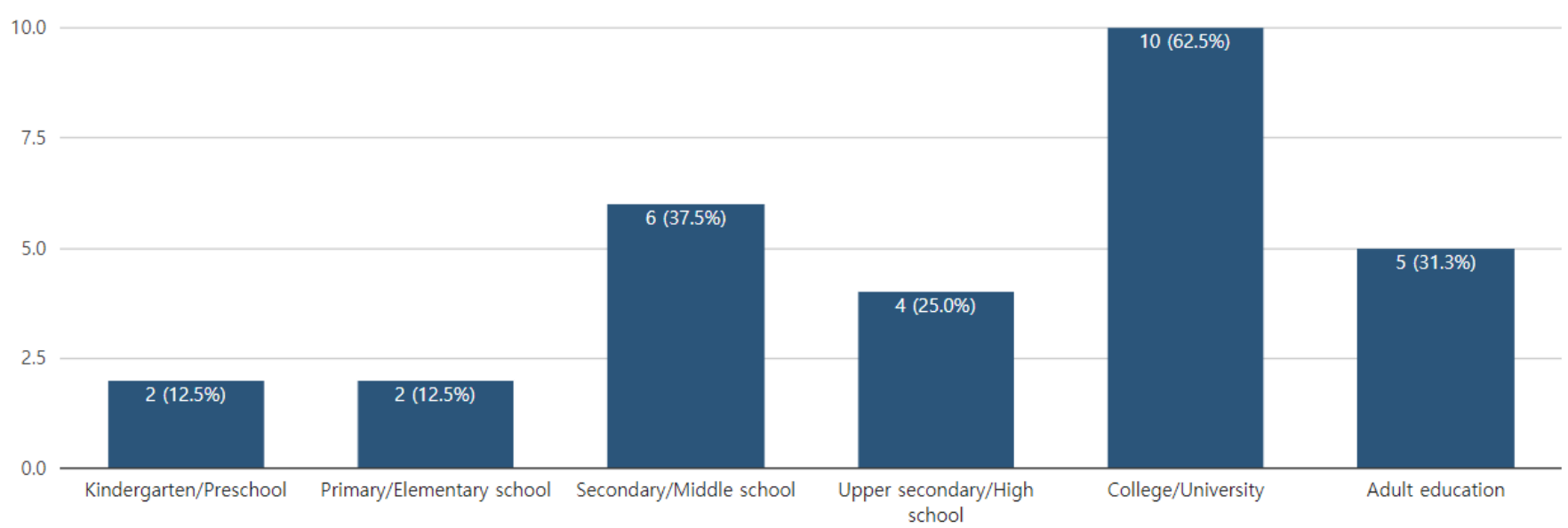

From the experiential teachers who recognize the existences of ELF, this study may be viewed from over teaching place where most of the participants $62,5 \%$ are teaching in college/university, 37,5\% in secondary/Middle school, 25\% from upper secondary/ high school teacher, and the following 12,5\% come from kindergarten/preschool teachers and primary/elementary school teachers.

\section{Data collection and analysis}

The Survey. Based on the participants' answers of 10 open-ended questions that were adapted from previous research (Kung \& Wang, 2019), the results analyzed narratively and categorized briefly to support the research questions.

The interview. The participants' interviews give an in-depth insight into how teachers perceive and practice skilled English. All participants were invited to the semi-instructed interviews. The analysis was carried out such that specific patterns could be collected by individuals data sets and commentaries that were special to particular participants. Coding from the participants' responses will lead to help the study's categorization and research concerns. Meanwhile, bracketing was used to point out the direct answer, which was related to the research question. A fundamental limitation of this study is to find it difficult to regard teachers who engaged in the interviews as representative samples. 


\section{FINDINGS AND DISCUSSION}

\section{The connection between $\mathrm{L} 1$ and $\mathrm{L} 2$}

The participants from different regions reflect the profile of the participants to their origin. The language skills history of the participants can tend to affect the findings. Thus, the chart Figure 4. reflected that top of the participants' L1 up to the less for this research were Bahasa Indonesia, Javanese, Sundanese, Arabic, Bengali, Banjarese, Akha, Vietnamese, and English. The fact from 16 participants, they use more than one language as the additional mastered language. Figure 5. emphasized that 15 participants chose English as their L2 language profile, followed by French 4 votes, Arabic and Bahasa Indonesia remind in the same priority for three people. German, Japanese, Mandarin are mastered by two people only. The rest of them acquire

Figure 4. Participants' $1^{\text {st }}$ Language

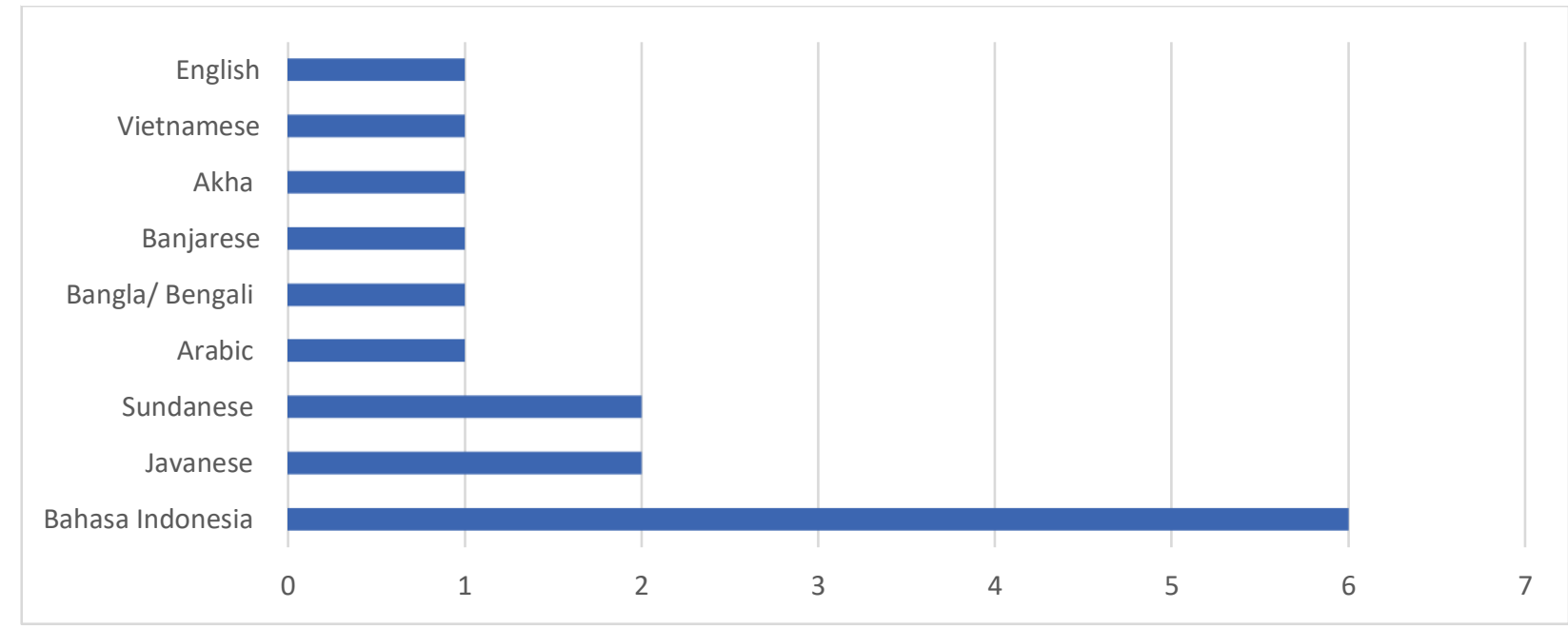

Thai, Hindi, Dutch, Spanish as the $2^{\text {nd }}$ language ability.

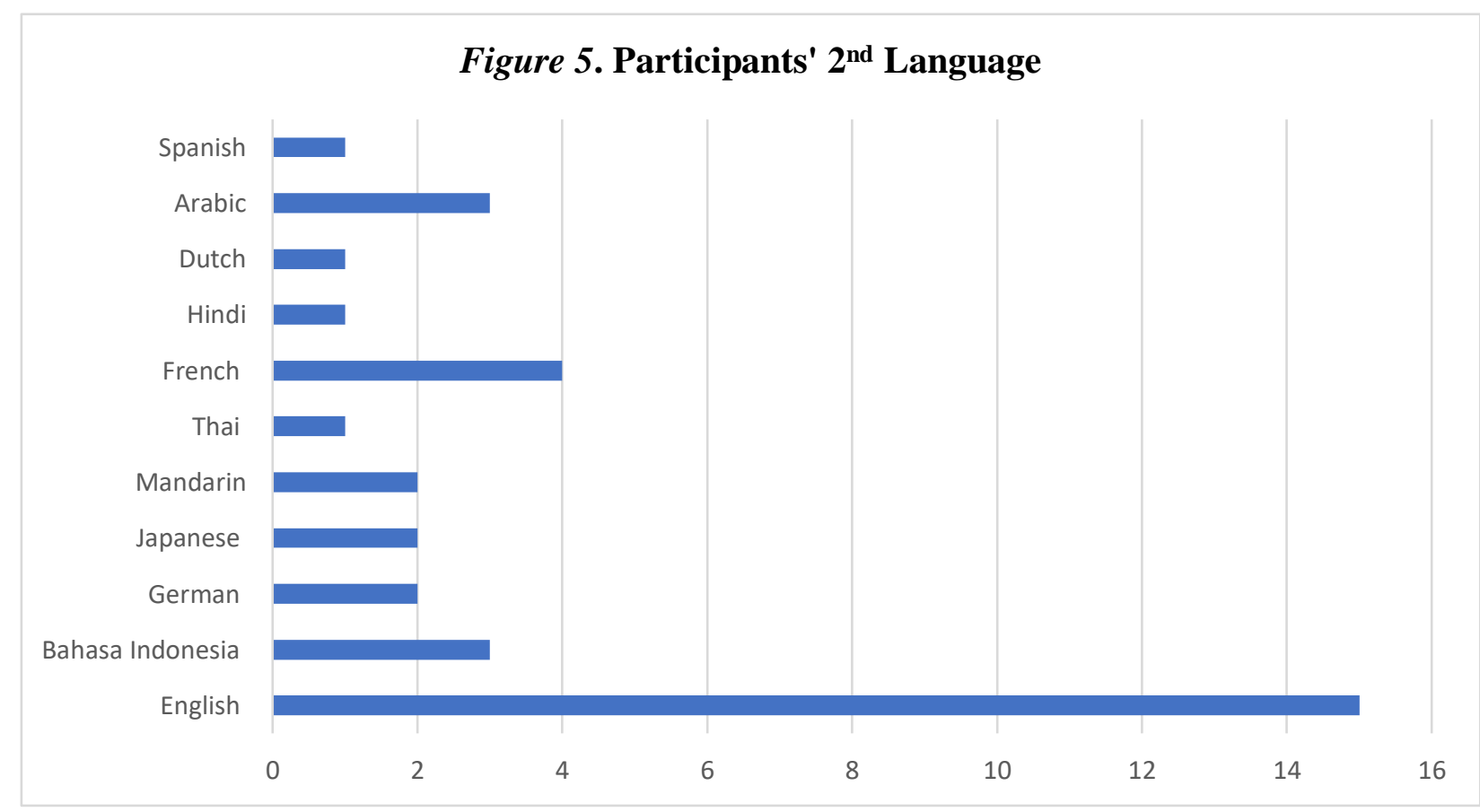




\section{The implications of teachers' background and the use of ELF to teach and communicate} The participants learn EFL from various activities and contexts. Most of them said the EFL experience got from education and classroom context, from native speakers, and family relationship since young. It showed when they said that

"I learn about native speaker, their accent $n$ culture. Also, I learn about my fellow teacher ability and my student ability. It encourages me to learn more about English."

"It was very awesome, I enjoyed the learning process through discussion and communication also did a presentation."

"[I learn English a lot when] I am teaching students at school as university program, private tutoring, working at a language course."

"I learned EFL since I was 2 years old."

In line with how participant immerses the language, it can also be seen when they try to be proactive autonomy to encourage master the language by several activities. It is listed through following formal discussion, presentation, make EFL project together, actively communicate with native directly or using smartphone's apps, daily conversation by ignoring grammar first, teaching practice, reading books/ papers/ magazines, watching movies, listening to radio/ podcast, sharing information, following workshops/ seminars/ conferences.

"By communicating with person and using smartphone apps." (P3)

"I learned it by studying with the teachers in the classroom, discussing with friends, practicing with the native speakers, etc." (P4)

"I learned through daily conversation with friends in the class and people who can speak English in the university. More importantly, $i$ guess $i$ learned elf in the WhatsApp chat as well since $i$ am the only one using other language and we use elf for communication. It means we tend to ignore grammar." (P5)

"By reading books. Studying at school up to university, by practicing and teaching" (7)

"After reading the English paper, magazine, and watching English movies and radio, I share the information to those who want to listen to me." (8)

“From courses in School and College and workshops.” (P9)

"I learned lesson plan during my university study for 1 semester, I joined workshop of formal English teaching-learning for a week in LPMP Jawa Timur (Institution of Education Development), I joined workshop for assessment K13 and joined an English Teacher Meeting (MGMP English) for Secondary school." (P10)

"I did A Celta and then had years of experience. I attended conferences and also worked with a publisher visiting English teachers in schools." (P11) 
The survey presents the responses from participants about the length of teaching which they have experienced (Table 1.) This evidence can be seen from the teaching experience that the participants are extremely experienced in teaching with the proven answer from P10 and P11. The participants were correlated with the lived experience (Table 1), L1, and L2 (Figures 4 and 5) as they responded to the question.

\section{Discussion}

The study set out to utilize accents contribution to the learners and the implication of the use of ELF in the teaching classroom. The attention areas focus on the attitudes towards the accent's preferences, the changes factors, and the role of ELF experiences. The qualitative was briefly adopted with surveys and interviews. The two research questions were addressed to contribute to further teaching implications.

\section{The general views of utilizing accents to the context of language learners}

While participants have a range of $\mathrm{L} 1$ and practice in interacting with the specific language as L2, their attitude towards language diversity was variated. The approach is to communicate can be driven by the study of data. They said that

"[...] because the most important is communicative, [so language accents does not matter.]"

"[...]it is a way to facilitate communication."

"[...] communication is a matter of understanding each other."

"It is interacting of two people who share different cultures, background, and language."

"Bridging me to communicate my ideas to other people and culture."

"[...] Not so crucial. Because for me, as secondary teacher, as long as it is understandable, it is okay to use different accents. Even when someone mix their accent because of different knowledge, that would be very nice to be learnt."

"To be honest, I think I have a positive attitude towards different accents. As I have been working with my colleagues from different countries (US, Mexico, Spain, France, Singapore, China, Philippine, and Indonesia), I have encountered various accents. Ifeel like no matter what accents people have as long as the purposes of communication are fulfilled. Therefore, accents are less important for me as long as people understand the meaning of what we say."

Learners' perceptions of English as the basis of comprehending the message was explicitly regarded. Different accents, as long as both speakers recognized, seemed appropriate. The pronunciation was the reverse of the goals in accents. Such participants claimed that

\footnotetext{
"Not accent, rather clear pronunciation matters."

"At higher level [...]From B2 [the fourth level of English in the Common European Framework of Reference] up to $C 2$ [the sixth and
} 
final level of English in the Common European Framework of Reference], I think exposure to different accents helps students learn and understand and more."

"[...] People have different tongue, and this affects their foreign language."

"It is important because accent will make people get interested to talk to us longer and more understandable. But it is not the most important thing for communication. If the accent is not like native like but the pronunciation is good, communication will still run well."

Since the interlocutors can choose to prioritize preferences in order to understand significance and meanings, different mother tongues can influence certain languages as most commonly used in this study, including English. Accent encourages the learner's approval to reveal a different term. The participant thus suggests the full analysis of the language, including the accents during the research. One explanation also is the possibility that it can provide more focus to the interlocutors, even if the accents are not perfect, the pronunciation is easy and straightforward; the conversation will be sufficient.

At some stage, the pressures exposed give improvements, the explanation for the modifications and the shift into the preference for accents is that the aim of the speakers to improve, more learning experience to immerse the language, the inspiration of native expression as the pattern, clarification and individuality of acceptances, back to the fundamental purpose of the interaction, to understand each one. All these considerations can be identified from the study of the interview participants. Some of them have mentioned, such as:

"I think there are two main factors that influence my attitude towards accent. First, it deals with my personal factor. I mean I am a person who loves to talk and share with people from different countries, languages, etc. I found that it was a fun way to learn English and improve my speaking skills. On the top of that, I have learned their valuable cultures. Let's say the way they eat, talk, dress, and ways of thinking. I used to make fun of Indian English accent, but my attitude was changed by my Indian English teacher who earned 5 different doctorate degree. He inspired and motivated me to see a good part of every single person, and of course, accent cannot define everything. Second, environmental factor. As I mentioned earlier that I have surrounded by people who share different cultures, languages, beliefs, and thoughts. It allows me to embrace all differences gradually and, importantly, accents. I am open up to learn their accents as they do in the same way. By doing this, I can build a strong rapport with them, and the intercultural exchange is constructed simultaneously."

"English as global language can be applied to different region with different accents. I am totally okay with that because every region have their own "uniqueness." 
"Learning ELF from the class triggers me to see and understand Englishes more. I think if we don't appreciate other accents, we don't appreciate ours own accent neither."

"Experience has made me think this way. Many people still think a native accents the best. I disagree. It does not matter. What is important is clarity."

Take a look back at table 1. Whether learners expend ages teaching English and studying the language in-depth for multicultural students is becoming less relevant because of the fascinating influences on accent preferences that World English recently introduced. The real aim of utilizing the language is to interpret the meaning.

"Language is accepted as long as you understand each other."

"Age. I used to think American or British accent is the best. Now, every part might have their own accent, and it acceptable worldwide."

The accent preferences of the teachers who work in the classroom also tend to be significant. It requires choices in Thai, Indonesian, or Javanese influences as the initial L1. Most of them settled on the likes of American accents. Others prefer to use a blend of L1 and Americans as a native speaker, to be Asian-Americans.

"Actually, it is hard to say which accent is better and best suits me. However, I would say it is better for anyone to know both American and British English in terms of vocabulary. Because, as we know they sometimes use different words for the same things. I think it enables us to avoid misunderstanding and make the flow of our communication with both English. For my preference, I would say, I would like to keep my Thai accent (which is not 100\% and hard to define) and mix with both accents. I think it matters how we pronounce words clearly and correctly, but how close we can imitate to native accents is optional."

"American. Since I am used to speak in American accent and mostly American accent is used by people in Indonesia both at school or movies."

It is essential to learn many accents, including American and British accents. Nonetheless, the decision to use or not to use it relies on the English language's proposal to connect with various L1s. English can be of use as a foreign language to relay the meaning of dialogue in the sense of multilingual studies. ELF is then implemented not only informally, but even within the school, which required a standardized language for all English requirements.

"I do not have any preference. The speaker needs to be clear so that we can understand him or her, that is all that matters."

"Mixed. Sometimes I use British, but in some cases, I use American. I explain both of the differences to my students to make it understandable." 
In conclusion, the predominant perspectives on the usage of accents in circumstances of language acquisition intentionally exceed the ELF target. In order to get the interpretation of its meaning, English is obtained rather than just relying on the accents and changing the grammar just to help the speaker realize what the speaker is attempting to suggest. The local language is dominant in the sense of the classroom and is multilingual as a variety of distinctions. Although there are interests in this sample as native speakers, the majority explain and use the ELF for efficient communications. The views are distinct from the interests of other researchers. However, the length of the teaching and the exposure overseas do not change the focus priorities. This evidence requires students to obey the laws of the language with an accent and pronunciation. Nonetheless, students and teachers are the focus of the usage of English as a local model, which is significant as a model for using English.

\title{
The implication of the use of ELF in the teaching classroom
}

Both participants were assisted by effective communication as the key focus of the ELF. Surprisingly, the correspondence was not only verbally, but also textually transmitted. There is 'negotiation' as the interlocutor acknowledges the various contexts. In previous research studies, it is represented that ELF behavior in different cultures occurs to understand many ways, but especially to demonstrate constructive approaches employed by speakers in conversations. This constructive approach was clarified through extension terms or interpretation of phrases, using gestures, body language.

\begin{abstract}
"In my opinion, one way to constitute effective ELF communication is negotiating meaning. As ELF communication mainly occur between people who have different cultural backgrounds, the meaning sometimes needed to be negotiated. For example, in my case, ELF is used in interacting with Indonesian friends (e.g. WhatsApp). There are times when they use words, phrases, or even symbols I never known before. So by telling the meaning or learning cultures, it may create effective ELF communication. Second, body language could be a good strategy when facing difficulty in language proficiency. For example, between foreign students and vendors or local teachers and foreign teachers. "
\end{abstract}

However, the findings mentioned above are also apparently different because of the students' accents pattern. At the same time, several participants opposed accents but then chose to express the exact truth in order to grasp its significance. That is because proper pronunciation can affect the language that has various interpretations such that negotiations can clarify the definition more precisely.

"I think understandable pronunciation. As I know, ELF is the process of communication between speakers who have different first language background, sometimes British and American are having different vocab pronunciation. For me is important since the way proper pronounce the word might be influenced by their language accent."

When the participants recognize the nature of ELF through their further statements that teaching as an area of study will play a crucial role in the perception of ELF objectives. English 
as language or as a teaching device allows the possibility to use the specific accents for bridging training for teachers and students.

"There are two periods of time in my life that I experience ELF communication. First, [...] where I work with foreign friends and second, during my study in Indonesia. In both places, English is functioned as a contact language between two people who share different mother tongues. In my view, English used as a working language or as a medium of instruction in the classroom allow me to feel comfortable and easier in that community. English in the work place increases my perspectives toward people, how they think how they work. Similarly, English in the classroom creates supportive learning environment which improve my English proficiency."

Teachers' understanding of how to satisfy students is seen in this response. Teachers often convey the speech in different forms to which students are referring. It makes the students feel concise and reluctant to answer because they do not understand the previous significances.

"Sometimes they pronounce some vocabulary differently and I have to make a confirmation of what they are saying about."

"It means being able to effectively make a listener understand what you want to say."

Therefore,

"It is very important because I am an English teacher and I actively communicate with people in this field thus without proper communication I will not be able to get along with them."

To maximize the usage of ELF in this theoretical context for efficient communication. ELF may be unrelated to the EFL classroom background when the grammatical and necessary functions as the foundations of a modern language are identified. Alternatively, ELF should only be used in diplomacy or other learning environments, such as public affairs, political and foreign ties, industry, global news media, and even science study. The accent is not necessarily a critical issue. However, the meaning conveyed by the speakers must be enhanced without any emphasis.

"ELF is prominent in international politics and diplomacy, international law, business, the media, and in tertiary education and scientific research.”

"Accent is not the mean point. How we deliver our language so that people understand is more important."

On the other side, the findings of this research broadened the understanding of the relationship between teachers and accents. As the World Englishes, thus, accents are not called subordinates. The accent and grammar of the ELTs for teaching English as L1/L2 as well as of teacher education and research were varied in the sense of the ELF meaning of teaching education. It is remarkable today, particularly when the majority of ELTs worldwide understand L2 English. 


\section{CONCLUSION}

Accents/pronouncements on teachers in subjects other than English were granted no attention. While this work was mainly focused on ELTs, the implications for teachers in other subjects were also significant. Within this imperialism, the radical mentality towards the usage of English became a result of this research. The first is to express the general feedback of ELF viewpoints. The talks during the discussion led to shifts in accents. That could be by describing a particular confusion dictionary more explicitly by voicing a body language or expression, or simply by expanding such terms and phrases further. For further recommendation, the significance of successful ELF usage in the EFL classroom from various teacher backgrounds will be relevant. The intensity and vulnerability will now have an appreciation of the value of ELF in bridging English as a communicative language with formal education.

\section{REFERENCES}

Alqahtani, A. (2012). Native speakers model or English as lingua franca core? An exploratory study investigating both issues in Arabic-speaking classrooms of English. Arab World English Journal, 4(1), 135-143. Retrieved from www.awej.org

Andersson, S. (2020). Pronunciation teaching in the Swedish EFL classroom. Malmö universitet/Lärande och samhälle.

Byrnes, D. A., Kiger, G., \& Manning, M. L. (1997). Teachers' attitudes about language diversity. Teaching and Teacher Education, 13(6), 637-644.

Carrie, E. (2017). 'British is professional, American is urban': Attitudes towards English reference accents in Spain. International Journal of Applied Linguistics, 27(2). https://doi.org/10.1111/ijal.12139

Chen, Y. S., Ren, W., \& Lin, C. Y. (2019). English as a lingua franca: From theory to practice. Language Teaching, 1-18. https://doi.org/10.1017/S0261444819000302

Cogo, A. (2012). English as a Lingua Franca: Concepts, use, and implications. ELT Journal, 66(1), 97-105. https://doi.org/10.1093/elt/ccr069

Danping, W. (2013). The use of English as a Lingua Franca in teaching Chinese as a foreign language: A case study of native Chinese teachers in Beijing. ResearchGate, 5(May), 85-102. https://doi.org/10.1007/978-94-007-6476-7

Floris, F. D., \& Renandya, W. A. (2020). Promoting the value of Non-Native EnglishSpeaking teachers. PASAA, 59(June), 1-18.

Ishikawa, T. (2020). Complexity of English as a Multilingua Franca: Place of Monolingual Standard English. In M. Konakahara \& K. Tsuchiya (Eds.), English as a Lingua Franca in Japan: Towards multilingual practices (pp. 91-109). https://doi.org/10.1007/978-3030-33288-4

Jenkins, J. (2006). Current perspectives on teaching world Englishes and English as a Lingua Franca. TESOL Quarterly, 40(1), 157-181. https://doi.org/10.2307/40264515

Kaur, J. (2018). The intelligibility of English in global contexts: Concepts, methods, findings and implications. Foreign Language Education Research, 22, 1-10.

Ke, I. C., \& Cahyani, H. (2014). Learning to become users of English as a Lingua Franca (ELF): How ELF online communication affects Taiwanese learners' beliefs of English. 
System, 46(1), 28-38. https://doi.org/10.1016/j.system.2014.07.008

Kirkpatrick, A. (2012). English in ASEAN: Implications for regional multilingualism.

Journal of Multilingual and Multicultural Development, 33(4), 331-344.

https://doi.org/10.1080/01434632.2012.661433

Kung, F. W., \& Wang, X. (2019). Exploring EFL Learners' Accent Preferences for Effective ELF Communication. RELC Journal, 50(3), 394-407.

https://doi.org/10.1177/0033688218765306

Kustati, M., Yusuf, Y. Q., Hallen, Al-Azmi, H., \& Sermal. (2020). EFL Teachers' Attitudes towards Language Learners : A Case of Multicultural Classrooms. International Journal of Instruction, 13(1).

Mays, N., \& Pope, C. (2019). 'Quality' in qualitative research. Critical Public Health, 211233. https://doi.org/10.1080/09581599408406252

Meerleer, D. M. (2011). Beliefs and attitudes towards English as a lingua franca: native and non-native pronunciation a Flemish and Walloon perspective. Ghent University.

Nagy, T. (2017). English as a Lingua Franca and its implications for teaching English as a foreign language. Acta Universitatis Sapientiae, Philologica, 8(2), 155-166. https://doi.org/10.1515/ausp-2016-0024

Rahayu, G. (2019). Indonesia EFL teachers' perceptions about teaching English as Lingua Franca. LangEdu Journal.

Reko, R. (2019). Attitudes towards English as a Lingua Franca: A comparative case study of ESL/EFL teachers in Finland and the USA.

Sung, C. C. M. (2014a). Accent and identity: Exploring the perceptions among bilingual speakers of English as a lingua franca in Hong Kong. International Journal of Bilingual Education and Bilingualism, 17(5), 544-557.

https://doi.org/10.1080/13670050.2013.837861

Sung, C. C. M. (2014b). Global, local or glocal? Identities of L2 learners in English as a Lingua Franca communication. Language, Culture and Curriculum, 27(1), 43-57. https://doi.org/10.1080/07908318.2014.890210

Teng, B., \& Sinwongsuwat, K. (2015). Teaching and learning English in Thailand and the integration of conversation analysis (CA) into the classroom. English Language Teaching, 8(3), 13-23. https://doi.org/10.5539/elt.v8n3p13

Tsang, A. (2020). Why English accents and pronunciation 'still' matter for teachers nowadays: A mixed-methods study on learners' perceptions. Journal of Multilingual and Multicultural Development, 41(2), 140-156. https://doi.org/10.1080/01434632.2019.1600528

Ur, P. (2010). English as a Lingua Franca: A Teacher's Perspective. Cadernos de Letras, 27, 85-92. Retrieved from http://www.letras.ufrj.br/anglo_germanicas/cadernos/numeros/122010/textos/c13012201 00penny.pdf

Wei, L. (2016). New chinglish and the post-multilingualism challenge: Translanguaging ELF in China. Journal of English as a Lingua Franca, 5(1), 1-25 